\section{An Investigation of the Reading Text \\ 'Pakistan Zindabad' (Long Live Pakistan): \\ Critical Discourse Analysis Perspective}

\author{
Sheeraz Ali \\ Institute of English Language \& Literature, University of Sindh, Jamshoro, Pakistan \\ E-mail: alisheeraz77@gmail.com \\ Bahram Kazemian (Corresponding author) \\ Department of English, Tabriz Branch, Islamic Azad University, Tabriz, Iran \\ E-mail: bahram_kazemian@yahoo.com \\ Faraz Ali Bughio \\ Institute of English Language \& Literature, University of Sindh, Jamshoro, Pakistan \\ E-mail: faraz.bughio@usindh.edu.pk
}

Received: August 15, 2015 Accepted: September 2, 2015 Published: September 3, 2015

doi:10.5296/10.5296/elr.v1i2.8160ＵRL: http://dx.doi.org/10.5296/elr.v1i2.8160

\begin{abstract}
This paper is a critical study in Critical Discourse Analysis paradigm of a Textbook prescribed for intermediate students (Second Language Learners) in Government Colleges affiliated to the Board of Intermediate and Secondary Education (BISE) Larkana, Sindh, Pakistan. The textbook contains selected texts to improve students reading skills integrated with writing activities. Each of the texts contains questions at the end to be answered. It is observed that the reading tasks are badly designed and there is no mental activity to involve students in the text discourse. The study focuses on critical discourse of the underlying text to inspect whether the text reading involves students in the critical discourse or not; it also attempts to analyze the Reading Text 'Pakistan Zindabad' to identify problems showing the gap and unawareness on the part of teachers and students regarding the critical discourse of the text in classroom reading context. It is also suggested that teachers need to bring about a
\end{abstract}


change in their traditional teaching methods in order to tackle the issue. The awareness of critical discourse analysis is recommended on the part of the teachers in order to analyze and understand the real meaning of the text. In result, it may develop the critical approach which is very essential for a reader.

Keywords: Critical discourse analysis, Reading text analysis, Hidden meaning, Syntactic structures, Academic setting, Social inequality, Political agenda, Mental process

\section{Introduction}

Introducing Critical Discourse Analysis (CDA) in an academic setting is somewhat significantly investigating communication through text and instruction (Fisher, 2001). It has been regarded as a new trend in the field of applied linguistics and language studies aiming at developing critical thinking skills by understanding and analyzing the discourse of a text in a classroom context. According to Paul and Elder (2006), the concept of critical thinking skill is to realize how language is used to convey ideologies for achieving certain purposes. The author's hidden intentions interpreted in a text require a great deal of efforts on the part of a reader to conceptualize the hidden discourse. Agreeing with the theoretical assumptions, there are academic implications on developing critical reading skills for a true understanding of information presented in a prescribed text.

Moreover, Critical Discourse Analysis (CDA) is primarily concerned with the study of language by highlighting the role of a power structure, dominance and inequality operated in a society. This approach emerged in 1970 as one of the academic disciplines investigating communication either verbal or non-verbal to explore something hidden. The academicians favour this approach for its practical implications on language teaching and critical thinking skills in their respective academic settings (Kazemian, 2015). There are a number of texts containing implicit knowledge about an ideology propagated among the masses. For Fairclough (1992b), text analysis includes decoding of information through lexis and pragmatics to understand author's intended message or meaning because this process draws a close attention on the analysis of a situation in which a text is produced.

Research in the field of CDA recommends a number of ways for evaluating texts and communication, for example, van Dijk (1998a), in his studies, suggests macro-level analysis of sociocultural issues including racism, gender inequality, and power dominance in society. The micro-level approach analyzes interaction, communication, and the use of language on account of transferring message in context (Ali \& Kazemian, 2015). There is a Meso-level study or approach of an intermediary type which bridges the gap between two approaches mentioned above. Van Dijk (1998a) further adds that the members of a social group participate in a communicative event by performing certain activities as participants of an institution such as schools, media, and legislation. All of these characteristics contribute discourse of a particular society as an outcome of shared knowledge based on personal and social cognition (p. 354).

Apart from structural patterns, the semantic perspective is more crucial pertaining to the hidden meaning and context of a text. It may inwardly be carrying through language that may 
be some sociocultural influences affecting the readers' mind or there may be a chance of popularization of any political agenda operating through these texts. Regarding Discourse Analysis, Fairclough's (1992a) findings may be more appropriate in addressing the social inequality, power or any political ideology manipulated by the writers, politicians and media institutions, but uncovering these problems require pedagogical application of training students develop critical reading skills.

In a recent research study, van Dijk (1998a) states areas/fields of discourse analysis such as pragmatic conversation analysis, narrative analysis, rhetoric or stylistics, sociolinguistics and ethnography or media analysis (p. 353). All of these analytic tools are employed to assess and ascertain the most influential aspects of language and culture producing discourse. On account of valuable inputs offered by Fairclough and Wodak (1997), showing discourse not only constitutes society but also performs an ideational function that is mediated between the media and masses, authors and readers.

By drawing a close distinction between the analysis of a conversation and news report, Fairclough (1995b) clarifies an organizational and structural pattern involved in the output of two expressions. He regards speech as a spontaneous flow of lexical sets and phrases creating oral structures repeatedly occurring during the conversation. On the contrary, written discourse is consciously fabricated in chunks for sequencing and organizing information. There are comparatively complex and long utterances than the short ones used in dialogues. Thus, the study of linguistic analysis may uncover how language acts during an interaction, but the study of Discourse Analysis raises critical awareness regarding linguistic knowledge implied in words and sentences to form meaning and ideas.

Reading Text Analysis may consider various issues related to the production and publication of information, and the discourse inside a variety of texts may serve diverse purposes of transmitting vision, culture and conventions. In fact, the flow of information is often found propagating writer's own assumptions about the world and its relationship with the exercise of power by dominant groups of society (Fairclough, 1995). Thus, the objective of CDA is to make contribution against social inequality and injustice, and highlight the importance of critical strategies required to equip readers with skills to understand the diverse functions of a text (Woods, 2006).

This study observes that discourse analysis is a process in which reader's and the listener's mind operate on linguistic features of an utterance to grasp the proposed meaning of writers or speakers. That meaning is implied into words and sentences to be conveyed to the receiver operating his mind on the expectation of understanding the message. The conversation may lead to confusion if the receiver is unfamiliar with the syntactic structures and their functions in determining the meaning in context, because implied sociocultural and political context not only control text but also convey a hidden message.

The arguments in this study discuss that the structure of a text is the combination of words, phrases and sentences. These smaller units are arranged coherently to form a pattern of organization in expository and descriptive writing. The use of discourse markers (but, because and, as...) keep on shifting ideas, shows contradictions, and reinforcement of an 


\section{N Macrothink}

argument in the text. Such are the set conventions followed to raise explicit awareness about the text structure. A paragraph of any length and type covering an article, essay or a news report is fundamentally a sort of discourse, and is often revealed by a statement of objective and topic sentence usually appearing at the beginning of a paragraph (Johnstone, 2008).

\section{Literature Review}

Discourse Analysis (DA) is an essential cognitive process of mental awareness regarding the written texts or spoken words used in context while reader goes through to understand a speech or text. It holds such an importance that even if one misses the single part, it would distort the whole connection related to semantic or pragmatic understanding of a discourse in any context. Wallace (1992) observes that readers in their classes are often found interacting with multiple texts more submissively rather than critically. In this regard, teachers are observed teaching texts of general interests that may not help learners develop critical thinking skills. However, CDA aims at changing this situation by offering them cognitive awareness to be confident and efficient readers.

The importance of textbooks being used for teaching reading skills in various academic settings is highlighted by Urquhart and Weir (1998). The texts used for reading classes keep a record of political and religious ideologies produced by authors and publishers for maintaining their hegemony and influence in society. The interpretation of data in textbooks not only disinterests a learner but also hinders the process of developing reading skills in the classroom context. Therefore, meaningful insights drawn from CDA make recommendations on introducing interesting and scientific texts for developing reading skills. The readers often come across multiple texts containing information about political and religious ideologies, and author's personal viewpoint about the world. However, discourse learning and critical thinking skills enable readers to understand the author's intended message in the text.

Development of critical thinking skills leads students to attain certain purposes of evaluating various texts by identifying its pattern and construction. The structure is often composed of paragraphs maintaining sequence and coherence to narrate a story, event or incident. The situation may include background information, general comments and conclusion. Paul and Elder (2006) contend that critical thinking is highly an intelligent attitude of mind requiring introspection and reflection of a reader or learner to evaluate and conceptualize the information gathered from contents and observation. Glaser (1995), on the other hand, adds that critical thinking is comprised of mental abilities such as identifying a problem and finding means to solve it. He also categorically speaks about a collection of relevant information forming opinions, presenting conventions, and discussing values to be comprehended by the reader. Later, there is a description regarding the issue of accuracy and evaluation of data supported by pieces of evidence to establish facts. Moreover, the use of logical relationships between statements leading to conclusions and generalizations may be tested with one's wider experience of knowledge and belief.

CDA fundamentally aims to evaluate the use of language in speech and written discourse implying an objective, belief, event or any philosophy. These utterances/expressions are transmitted through a particular speech in context shaping the writer/speaker's discourse 
having a hidden intention. In order to understand the deep meaning, critical readers apply analytical tools aiming to evaluate events, people, and objectives in producing such texts. It is, therefore, essential for readers to understand the context before analyzing text in the classroom context. (Thompson, 2001).

Development of critical thinking skills is fundamentally a pedagogical process involving a great deal of efforts on the parts of academicians and language practitioners to introduce discourse learning and critical reading in their respective classroom settings. It can be made possible by involving students in a mental process aiming to enhance comprehension and critical skills. At an initial stage, they may be exposed to the texts of general interest attracting learners' attention on the ability to identify main parts of a text, such as introduction, middle, and the conclusion. It is a higher level mental activity requiring proper instructions for performing reading tasks on encountering an issue and questioning it in the classroom context. These strategies not only improve reading efficiency but also enable learners to understand the text comprehensively and critically.

\section{Text Analysis of Intermediate English Book-I}

\subsection{Textbook Evaluation}

This intermediate English Book-I is prescribed by Sindh Textbook Board Jamshoro for all public sector colleges of Sindh province. The course book is used to teach English as a compulsory subject to the students of Higher Secondary School Certificate level (HSC). It consists of texts ranging from political history, humor, adventure to the earlier scientific inventions. Many of the units are selected from literary publications of different authors. These texts in the course are designed for mixed language proficiency level students addressing their general needs and interests. An objective analysis of this book is to develop students' reading skills by solving comprehension exercises containing ten information-based questions in each text.

\subsection{Microstructure Analysis}

In view of Van Dijk's theory of structural analysis of a text description (1998a), evaluating the first reading text titled as Pakistan Zindabad is prominently holding an ideology of a state. The first part is served to set background information of an aircraft landed at Mauripur airport, and the man appeared first was Quaid-i-Azam. In addition to the description of a personality, there are lexical sets and phrases such as tall, dignified and elderly present the qualities of a person rather than a leader. Later on semantic grounds, the text interprets some emotional aspects causing reading hindrance to understand the excitement of people welcoming their leader and his response to them as calm, serious and even severe.

Moreover, the author uses certain expressions to maintain the dominant role of Quaid-i-Azam as a leader to represent the voice of Muslims. On account of semantic analysis, most of the phrases lack logical meaning in the text. For instance, the clause (tired and far from well) implies author's intention of showing illness and old age. It can also be assumed that no longer Quaid would continue working for his people. Similarly, the phrase (greater part) indicates towards the establishment of a Muslim state which may, in fact, be the smaller part, 
because development was needed for a new state. Thus, the vague interpretation of ideas may lead to confusion and distort discourse of a text.

The second part of the text briefly draws the picture of Pakistan Movement and goals behind this struggle. In relation to the structural analysis of sentences, there are pieces of evidence describing a historical event such as Pakistan Resolution and its decision to demand for a new state for the Muslims of the subcontinent. There is the transcription included in the text of Quaid-i-Azam's speech to the League for asking members to take a firm "decision and stand by it as one man". Certainly, the words strongly show the force of determination on the part of speaker declaring "no power on earth can prevent Pakistan". The confusion arises when Lord Mountbatten quickly decides that "India must be divided into two states". It is therefore left up to the readers' understanding of discourse to know the hidden message contained in words of a British ruler and Muslim leaders.

In another paragraph, the author shows biased attitude by using the following utterances:

1) Jinnah was as usual very severe and firm, faultlessly dressed; Gandhi wore his familiar white Dhoti and sat on the floor. The one was Muslim first and last, the other a Hindu to his finger-tips. Jinnah might have said then what he once said of the Hindus and Muslims: "we are different creatures. There is nothing in life that joins us together". (p-3)

The lines above are the writer's personal opinion about people regarding their outward appearance and behaviour. In fact, the utterance contains negative influence which the writer has not taken care of. It is rather a writer's own liking and disliking towards the treatment of above characters making it biased and unfair, as the obvious presentation of Jinnah makes Gandhi inferior to him. Thus, the choice of language structures carrying wrong information in a course book not only distorts the message of discourse but also creates confusion for readers to understand the message.

\subsection{Macrostructure Analysis}

According to Van Dijk (1998), discourse is not simply an isolated version of a text. It rather involves complex communicative features creating context to process the inward meaning and message. In view of the writers' statement, the context of the first reading text from its title Pakistan Zindabad (long live Pakistan) is the freedom of people demanding an independent Muslim state. The part one contextualizes the role of Quaid-i-Azam as a leader of Muslim Community in the united India. He protects their rights and culture as an advocate of the masses belonging to Islam as religious faith. In the next part, there are sociopolitical details related to Muslim League as a representative political party and a Resolution deciding to part India into two states.

Most of the researchers regard context as a key feature of any text to understand hidden meaning (Kazemian et al., 2013; Kazemian \& Hashemi, 2014a, b; Noor et al., 2015 etc.). In relation to the ideological assumption, this text prominently holds a political and religious ideology of a Muslim state. The language and discourse uncover some hidden agenda of defending the cause of Muslims and their victimization by a majority. A major portion of the text is being served for the propagation of separate state where the believers of Islam can 
freely practice their religion. Moreover, the writers considers it as a fundamental right for which a new entity is demanded by the representative of Muslims. They also include that the two communities greatly differed in their sociocultural and religious practices, but there was a time when they had lived together for more than one thousand years when Muslims ruled the subcontinent who, in fact, were invaders.

Following the context, it is imperative to testify the facts illustrated by the producer producing information through language (Fairclough, 1990). The writers thinks Islam as one of the sacred religion of the world. Holding such supremacy of belief is an important aspect of sharing knowledge and experience with the readers/audience. This may not be considered as an authentic fact because people follow different religions and they practice it in accordance with their cultural values. It is important therefore that the readers are aware of sociocultural and political conditions influencing authors to produce text.

Apart from representing faith and political description, there are details showing author's biased attitude in depicting the wrong picture of Gandhi as he was not in favour of splitting India due to the unanimous homogeneity of cultural values inhibited by both Muslims and Hindus. Not going into historical depth, it is quite pertinent to mention that the two communities, i.e. Hindus and Muslims, were equal shareholders of the civilization of India. However, the conversion to new faith parted them from each other and their single entity. Finally, the political dispute was resolved by parting India in two separate states. These days, there are millions of Muslims living in India than Pakistan.

\section{Findings and Discussion}

CDA of the reading text titled as Pakistan Zindabad highlights key issues related to the manipulation of politically biased information. The problems identified in the discourse have future implications on the establishment of critical thinking skills at intermediate academic level. After analysis, the outcomes suggest that the text selection is faulty lacking interest and motivation for Foreign Language Learners.

It does not appropriately address language and academic needs of students encountering scientific information in prescribed courses of studies at the same level. The use and relevance of English texts for the learners' educational goals need immediate attention for revision, adaptation and possible innovation. This process requires teachers/educators to replace the existing practice of teaching English as Foreign Language, particularly reading skills.

Fundamentally, the existing course of English has no teaching/learning objectives mentioned in units. As regards reading text One, it primarily focuses on information rather than the development of language and reading skills. The learners, on the other hand, may find the contents disinteresting, old and outdated. Apart from the subject matter, there are faulty Grammar exercises having no functional integration with language skills. These mainly aim at memorizing descriptive rules related to the structures. It is because of shortcomings, a good number of students not only show a lack of interest but also hesitate to participate in classroom activities. Thus, the overall objective is not served as the course has no relevance 
with another scheme of studies.

Moreover, the text contains an information-based activity, it is a comprehension exercise comprising of ten questions. The readers are expected to locate and reproduce facts by using clues in rephrasing and reproducing data at the sentence level. The writing tasks in the text ask learners to write without proper guidance which proves very discouraging because learners fail to write without context.

One of the major reasons discouraging critical reading is the use of historically biased information. One such example is already mentioned in reading text one describing Hindu/Muslim controversy over parting India into two states. Discourse learning as an innovative approach requires a great deal of investigations into the process of communication. The researchers elaborate it as the complex phenomenon of mind involving socio-psychological factors stimulating interaction. It is, therefore, necessary on the part of reading teachers to introduce critical strategies that can help students identify, evaluate and synthesize information of reading texts.

\section{Conclusion and Recommendations}

\subsection{Conclusion}

In the light of above discussion and the literature reviewed, it can be concluded that critical discourse analysis aims at developing critical approach by improving higher level thinking skills. It is an emerging trend in the field of language teaching and communication studies. The professionals opting for this innovation may find it quite useful for foreign language readers having less acquaintance with English texts. As a result, they either rely on the translation or the explanation of a text by the teacher to understand its meaning in their native language. The teaching methods applied in many of reading classes do not support learners in deducing the meaning from context. In order to build this ability, it is necessary that language teachers should be aware of teaching critical reading skills so as to help their learners become independent and efficient readers. Therefore, professional development of teachers may be considered as an important aspect of raising awareness regarding discourse learning and critical thinking that ultimately improves academic quality, learners' performance, and their mental attitude as social beings.

It has been observed that the majority of teachers lack the ability to design reading tasks for improving critical reading skills. It is also mentioned earlier that the textbook does not mention the course objectives, and lacks reading discourse tasks, and emphasizes on faulty comprehension, composition and grammar activities. These gaps in the textbook can only be addressed by the trained, qualified, and experienced teachers in the English language teaching. It is therefore obligatory for stakeholders and policy makers to make changes in the textbook and give due space to the professional development of teachers in the field of English language teaching.

On account of the above discussion, the research findings can bring about a significant change in the field of education from memory-based practices to the development of cognitive learning focusing on higher level thinking skills. This process involves an exposure 
to vast reading texts and tasks contributing awareness regarding the use of information in reading texts critically. Therefore, discourse learning and critical thinking may be integrated as an innovative teaching strategy in educating learners to become critical readers of prescribed textbooks.

\subsection{Recommendations}

Intermediate English Book One prescribed for Higher Secondary students of the first year is old and outdated, it is still used which is very strange. The analysis brought before us drawbacks and shortcomings. Therefore, it needs to be changed to introduce text that meets the modern needs to develop critical discourse analysis. In view of discussion and findings, it is recommended that:

* Education \& Literacy Department Government of Sindh, Pakistan should provide and arrange professional development opportunities/programmes for the teachers of English working in public sector colleges of Sindh province.

* Curriculum designers need to pay attention to revise Intermediate English Textbook for addressing the language needs of foreign language learners.

* Heads of the institutions should arrange workshops and seminars on contributing awareness about the exploitation and adaptation of current textbooks in their teaching and learning context.

* Reading teachers may introduce meaning and context-based teaching strategies to facilitate learning in developing reading skills.

\section{References}

Ali, S., \& Kazemian, B. (2015). Critical Discourse Analysis of a Reading Text 'Pakistan and the Modern World': A Speech by Liaquat Ali Khan. Communication and Linguistics Studies, $1(3), 35-41$.

Fairclough, F. N. (1990). Critical Discourse Analysis: The Critical Study of Language. London: Longman.

Fairclough, N. (1992a). Discourse and Social Change. Cambridge: Polity Press

Fairclough, N. (ed.) (1992b). Critical Language Awareness. London: Longman.

Fairclough, N. (1995). Media Discourse. London: Edward Arnold.

Fairclough, N., \& Wodak, R. (1997). Critical Discourse Analysis. In T. A. Van Dijk (Ed.), Discourse Studies: A Multidisciplinary Introduction. Vol. 2. Discourse as Social Interaction. (pp. 258-84). Cambridge: Polity.

Fisher, A. (2001). Critical Thinking: An Introduction. Cambridge: Cambridge University Press.

Glasser, T. L., \& Salmon, C. T. (Eds). (1995). Public Opinion and Communication of Consent. NewYork: Guilford Press. 


\section{Macrothink \\ Education and Linguistics Research \\ ISSN 2377-1356 \\ 2015, Vol. 1, No. 2}

Johnstone, B. (2008). Discourse Analysis. Cambridge: Cambridge University Press.

Kazemian, B. (2015, Jul. 15). [Review of the book Describing discourse: A Practical guide to discourse analysis, by Woods, Nicola, 2006]. Asian Journal of Communication, 25(5).

Kazemian, B., Behnam, B., \& Ghafoori, N. (2013). Ideational grammatical metaphor in scientific texts: a Hallidayan perspective. International Journal of Linguistics, 4(4), 146-168. http://dx.doi.org/10.5296/ijl.v5i4.4192

Kazemian, B., \& Hashemi, S. (2014a). Nominalizations in scientific and political genres: A systemic functional linguistics perspective. International Journal of Humanities and Social Sciences (IJHSS), 3(2), 211-228.

Kazemian, B., \& Hashemi, S. (2014). Critical discourse analysis of Barack Obama's 2012 speeches: Views from systemic functional linguistics and rhetoric. Theory and Practice in Language Studies (TPLS), 4(6), 1178-1187. http://dx.doi.org/10.4304/tpls.4.6.1178-1187

Noor, M., Ali, M., Muhabat, F., \& Kazemian, B. (2015). Systemic Functional Linguistics Mood Analysis of the Last Address of the Holy Prophet (PBUH). International Journal of Language and Linguistics. Special Issue: Critical Discourse Analysis, Rhetoric, and Grammatical Metaphor in Political and Advertisement Discourses, 3(5-1), 1-9. http://dx.doi.org/10.2139/ssrn.2604000

Paul, R., \& Elder, L. (2006). Critical Thinking. New Jersey: Pearson Prentice Hall.

Thompson, G. (2001). Introducing Functional Grammar. London: Edward Arnold.

Urquhart, S., \& C. Weir. (1998a). Reading in Second Language: Process, Product and Practice. London: Longman.

Van Dijk, T. A. (1998a). Ideology A Multidisciplinary Study. London: Sage.

Van Dijk, T. A. (1998b). Opinions and Ideologies. In B. Allan \& P. Garret (Eds.). Approaches to Media Discourse. Oxford: Blackwell.

Wallace, C. (1992). Critical Literacy Awareness in the EFL Classroom. In N. Fairclough (Ed.), Critical Language Awareness. (pp. 59-92) London: Longman.

\section{Copyright Disclaimer}

Copyright reserved by Sheeraz Ali, Bahram Kazemian \& Faraz Ali Bughio.

This article is an open-access article distributed under the terms and conditions of the Creative Commons Attribution license (http://creativecommons.org/licenses/by/3.0/). 